\title{
Pengembangan Soft Skills Siswa Melalui Penerapan Culturally Responsive Transformative Teaching (CRTT) dalam Pembelajaran Kimia
}

\author{
Yuli Rahmawati $^{1 *}$, Achmad Ridwan ${ }^{1}$, Sylvia Faustine ${ }^{1}$, Pramita Cucu Mawarni $^{2}$ \\ ${ }^{1}$ Universitas Negeri Jakarta, Jl. Rawamangun Muka, Jakarta, Indonesia, \\ ${ }^{2}$ SMA Bakti Mulya 400, J1. Lingkar Selatan, Pondok Pinang, Jakarta, Indonesia
}

DOI: $10.29303 /$ ippipa.v6i1.317

Citation: Rahmawati, Y., Ridwan, A., Faustine, S., \& Mawarni, P. (2020). Pengembangan Soft Skills Siswa Melalui Penerapan Culturally Responsive Transformative Teaching (CRTT) dalam Pembelajaran Kimia. Jurnal Penelitian Pendidikan IPA, 6(1). pp. 86-96

\section{Article history}

Received: September $23^{\text {th }} 2019$

Revised: December $10^{\text {th }} 2019$

Accepted: January $17^{\text {th }} 2020$

*Corresponding Author: Yuli Rahmawati: Universitas Negeri Jakarta, Jl. Rawamangun Muka, Jakarta, Indonesia. Email: yrahmawati@unj.ac.id

\begin{abstract}
This study aimed is to develop students' soft skills through the implementation of the Culturally Responsive Transformative Teaching (CRTT) in chemistry learning. Indonesia's ethnic and cultural diversity is a challenge for teachers to design the chemistry lessons which is relevant with students' characteristics. The research methodology applied is qualitative and applied on chemistry learning in the topics of acid and base, electrolyte and non electrolyte solution in five stages: self identification, cultural understanding, collaboration, critical reflections, and transformative construction. This research was conducted in two schools in DKI Jakarta and West Java in 2018. The data was collected by interview, reflective journal, and observations. The results showed that the chemistry learning through CRTT model can develop students' soft skills such as collaboration skills, critical thinking skills, nationality, social and cultural awareness, leadership, environmental caring, and curiosity. The teachers' interview and reflections showed that the challenges in applying this approach were creativity in integrating cultural concepts in chemistry learning, students' understanding, time constraints, and the paradigm of students and teachers. Integration of ethnochemistry in CRTT can be developed in other chemical concepts with the principle of students' character development.
\end{abstract}

Keywords: Acid and base; Culturally Responsive Transformative Teaching (CRTT); Electrolyte and non electrolyte solution; Ethnochemistry; soft skills.

Abstrak: Penelitian ini bertujuan untuk mengembangkan soft skills siswa melalui penerapan model pembelajaran Culturally Responsive Transformative Teaching (CRTT) pada pembelajaran kimia. Keberagaman suku dan budaya Indonesia menjadi tantangan bagi guru untuk merancang pembelajaran kimia yang sesuai dengan karakteristik siswa. Metode penelitian yang digunakan dalam penelitian ini adalah kualitatif dan diaplikasikan dalam pembelajaran kimia dengan topik asam dan basa, elektrolit dan non-elektrolit dalam lima tahapan pembelajaran CRTT yaitu identitas diri, pemahaman budaya, kolaborasi, berpikir refleksi kritis, dan konstruksi transformatif. Penelitian ini dilakukan pada dua sekolah di DKI Jakarta dan Jawa Barat, pada tahun 2018. Teknik pengumpulan data menggunakan wawancara, reflektif jurnal, dan observasi. Hasil penelitian menunjukkan pembelajaran kimia melalui pendekatan CRTT terintegrasi etnokimia dapat mengembangkan soft skills siswa seperti bekerja sama berpikir kritis, cinta tanah air, kesadaran sosial dan budaya, kepemimpinan, peduli lingkungan, dan rasa ingin tahu. Hasil wawancara dan refleksi guru menunjukkan bahwa tantangan dalam penerapan pendekatan ini adalah kreativitas guru dalam mengintegrasikan konsep budaya dalam pembelajaran kimia, pemahaman siswa, keterbatasan 
waktu, serta perubahan paradigma siswa dan guru. Pendekatan CRTT selanjutnya dapat dikembangkan dalam beberapa konsep kimia dengan prinsip pengembangan karakter siswa.

Kata Kunci: Asam dan Basa; Culturally Responsive Transformative Teaching (CRTT); Elektrolit dan non elektrolit; Etnokimia; Soft skills.

\section{Pendahuluan}

Bangsa Indonesia merupakan bangsa yang majemuk dengan kekhasan suku dan budaya dengan beragam latar belakang yang berbeda (Kemdikbud, 2016). Indonesia memiliki lebih dari 1.300 suku bangsa dengan jenis yang beragam, dengan jumlah populasi setiap suku bangsa juga sangat bervariasi, suku jawa menjadi suku yang paling mendominasi (Badan Pusat Statistik, 2010). Namun era globalisasi telah berdampak kepada lunturnya kebudayaan dan identitas budaya di Indonesia (Mubah, 2011). Menurut Otasevic (2013), arus globalisasi berdampak pada hubungan seseorang terhadap lingkungan dan budayanya, termasuk bahaya budaya homogenisasi dan pola dominasi budaya barat. Hal juga berdampak kepada generasi muda pada lunturnya nilai-nilai nasionalisme (Suryono, 2008). Pelestarian budaya sebagai antisipasi dampak globalisasi melalui berbagai aspek perlu terus dikembangkan.

Salah satu aspek yang dapat mengembangkan identitas budaya sebagai sarana untuk melestarikan budaya, khususnya pada generasi muda adalah melalui pendidikan. Dalam penelitian ini siswa diberikan model pembelajaran CRTT yang diintegrasikan dengan etnokimia dimana di dalamnya mengaitkan budaya daerah dengan mata pelajaran siswa di sekolah dan mengembangkan soft skills siswa. Tantangan pendidikan pada era globalisasi telah mendorong pemerintah mengembangkan berbagai upaya untuk mengembangkan identitas budaya siswa (Rahmawati \& Taylor, 2015). Salah satunya pada Peraturan Menteri Pendidikan dan Kebudayaan berkaitan dengan implementasi kurikulum 2013 melalui pelajaran muatan lokal untuk dapat mengenalkan siswa dengan lingkungan sosial, alam dan budayanya. Sehingga, keberagaman suku dan budaya Indonesia menjadi tantangan bagi pendidik untuk merancang pembelajaran yang disesuaikan dengan keberagaman Indonesia, karakteristik, dan latar belakang budaya siswa.

Pendidikan karakter yang menjadi landasan kurikulum 2013 memberikan kesempatan untuk membawa unsur identitas budaya dan pembentukan karakter di dalam proses pembelajaran. Pendidikan dapat menjadi unsur penting dalam upaya melestarikan budaya bangsa, karena tanpa adanya keterlibatan pendidikan, budaya lokal akan dihilangkan oleh modernitas masyarakat (Arifah, 2014). Arthur dan Wilson (2010) juga menekankan bahwa pendidikan seharusnya menghasilkan pekerja yang professional serta warga negara yang berkualitas, yaitu tidak hanya generasi yang memiliki pengetahuan, namun juga kemauan untuk terus belajar serta kemampuan personal dan nilai-nilai yang dimiliki. Sehingga sekolah berperan penting dalam membangun karakter dan budaya siswa, khususnya menghadapi permasalahan di masyarakat yang semakin kompleks serta semakin multikultur (Hutcheon, 1999). Selama pembelajaran, siswa diidentifikasi berbagai soft skills dan hard skills yang muncul. Soft skills sendiri dapat memengaruhi hubungan interpersonal, kinerja, dan prospek karir (Marcial, 2012). Hubungan interpersonal ini dibutuhkan untuk membangun hubungan dengan orang lain, dimana soft skills juga melibatkan kemampuan kepemimpinan, bekerja sama, kemampuan mengolah emosi dan mengatasi stress (Deepa \& Manisha, 2013).

Pembelajaran berbasis budaya telah dikembangkan oleh Aikenhead (2000) untuk menciptakan pembelajaran bermakna adalah dengan mengaitkan pembelajaran dengan latar belakang budaya siswa. Budaya adalah pusat bagaimana semua pembelajaran terjadi (Gay, 2010). Di kelas di mana pedagogi yang responsif secara budaya dipraktikkan sebagai jembatan yang menghubungkan siswa, guru, sekolah, dan masyarakat. Pendidik harus menyadari bahwa terdapat kaitan erat antara budaya dengan cara berpikir siswa (Gay, 2000). Integrasi latar belakang budaya siswa merupakan upaya untuk mendekatkan peserta didik dengan konteks pembelajaran dan kesadaran siswa terhadap identitas budayanya (Ladson \& Billings, 1995; Rahmawati \& Ridwan, 2017; Rahmawati \& Taylor, 2017).

Salah satu model pembelajaran yang dapat diterapkan dalam pembelajaran adalah CRTT yang dikembangkan oleh Rahmawati \& Ridwan (2017) and Rahmawati, et. al. (2019) berdasarkan prinsip CRTT dan pembelajaran transformative yang terdiri dari 5 fase yaitu identifikasi diri (self identification), pemahaman budaya (cultural understanding), kolaborasi (collaboration), berpikir refleksi kritis 
(critical reflection), dan konstruksi transformatif (transformative construction). CRTT diadaptasi dari $C R T$ yang merupakan pendekatan pembelajaran yang menghubungkan latar belakang siswa, pengalaman siswa, gaya belajar, dan karakteristik siswa untuk kepentingan akademiknya (Gay, 2000).

Gay (2000) mendefinisikan CRT sebagai cara menggunakan pengetahuan budaya, pengalaman sebelumnya, dan gaya belajar siswa yang beragam untuk dapat menimbulkan pengalaman belajar yang bermakna. Pendekatan $C R T$ juga merupakan cara siswa untuk memperoleh pengetahuan baru melalui lingkungan sekitar dan latar belakangnya (Cartledge \& Kourea, 2008; Gay, 2009; Ladson \& Bilings, 1995). Sehingga, penerapan pendekatan ini akan menekankan pada berbagai teknik yang terkait dengan integrasi budaya dan latar belakang, serta karakteristik siswa.

Pembelajaran kimia merupakan salah satu mata pelajaran dalam struktur kurikulum 2013 yang bertujuan untuk mencapai kompetensi yang tertuang dalam Standar Isi pada Permendikbud, No 21 Tahun 2016. Pencapaian kompetensi ini tidak terlepas dari strategi, model, teknik serta metode yang sesuai dengan karakteristik siswa, serta tidak terlepas dengan karakteristik ilmu kimia. Ilmu kimia adalah ilmu yang mempelajari materi, meliputi susunan, sifat-sifat dan perubahannya, serta perubahan energi yang menyertai perubahan materi tersebut (Chang, 2003). Pembelajaran kimia sebagai proses interaksi antara peserta didik dengan pendidik dan sumber belajar perlu dikaitkan dengan latar belakang budaya siswa, sehingga relevan dengan kehidupan siswa untuk menghasilkan pembelajaran bermakna (Taber, 2002; Gabel, 1999; Koballa, 2011). Studi sebelumnya pada pendekatan pembelajaran dengan dilemmas stories menunjukkan bahwa pembelajaran kimia di sekolah belum sepenuhnya mengkaitkan dengan latar belakang budaya siswa (Rahmawati, Nurbaity, \& Marheni, 2014).

Integrasi $C R T T$ dalam pembelajaran kimia yang dikembangkan pada penelitian ini adalah melalui integrasi etnokimia (ethnochemistry). Etnokimia sebagai salah satu cabang ilmu kimia yang mempelajari ilmu kimia berdasarkan perspektif budaya. Etnokimia merupakan bagian dari etnosains yang melibatkan berbagai disiplin ilmu yang berbeda antara ilmu-ilmu sosial dan humaniora (misalnya, antropologi, sosiologi, psikologi, dan filsafat) dengan ilmu alam seperti biologi, ekologi, dan kimia (Atran, 1991). Penelitian terkait etnosains telah dilakukan dalam pembelajaran di Indonesia yang terkait dengan pendidikan budaya berbasis budaya lokal (Suastra, 2005; Sarwanto, \& Budiharti, 2013), dan dampaknya terhadap literasi sains (Nisa, Sudarmin, \& Samini, 2015), minat dan prestasi belajar siswa (Shidiq, 2016), dan hasil belajar, serta entrepreneurship (Sudarmin,
Febu, Nuswowati, \& Sumarni, 2017). Penelitian etnokimia pada umumnya terkait dengan eksplorasi keterkaitan kimia dengan budaya, seperti penelitian etnokimia dalam budaya Baduy oleh Nursaadah, dkk (2017), sedangkan penelitian terkait dalam terhadap integrasi etnokimia dalam pembelajaran belum dikaji secara mendalam. Hal ini juga didukung oleh penelitian sebelumnya yang menerapkan pembelajaran berbasis budaya sebelumnya, hasil menunjukkan bahwa peserta didik lebih terlibat dalam pembelajaran kimia ketika hal itu berkaitan dengan kehidupan sehari-hari mereka (Rahmawati \& Ridwan, 2017).

Penelitian ini merupakan hasil penelitian tahun kedua dari pengembangan model pembelajaran dengan pendekatan CRTT. Tahun pertama penelitian ini telah menghasilkan model pembelajaran yang diterapkan menyang merupakan perluasan model pembelajaran CRTT yang telah diterapkan di dua sekolah di Jakarta dan Jawa Barat. Karakteristik sekolah yang berbeda antara SMA Negeri dan Swasta dan provinsi yang berbeda memberikan gambaran penerapan model pembelajaran yang sedang dikembangkan. Hasil penelitian tahun pertama telah dipublikasikan, sehingga hasil penelitian tahun kedua pada studi kasus di dua sekolah diuraikan pada artikel ini.

Penelitian ini dilaksanakan dengan harapan yaitu pengembangan soft skills siswa di era globalisasi yang tetap mencerminkan identitas budayanya melalui pelaksanaan model pembelajaran CRTT dalam pembelajaran kimia.

\section{Metode}

Penelitian menggunakan metode kualitatif dengan teknik pengumpulan data berupa wawancara, observasi, dan reflektif jurnal. Partisipan yang terlibat dalam penelitian ini adalah 65 siswa kelas $X$ yang berasal dari dua sekolah di DKI Jakarta (SMA A) sejumlah 34 siswa dan Jawa Barat (SMA B) sejumlah 31 siswa. Jumlah siswa yang terlibat di kelas XI berjumlah 68 siswa yang terdiri dari masing-masing 34 siswa dari kedua sekolah. Sehingga total partisipan terdiri dari 133 siswa dan guru yang terlibat dalam masing-masing kelas.

Pada penelitian ini pembelajaran pada topik Asam Basa dilakukan pada kelas XI, sedangkan topik larutan elektrolit dan non elektrolit dilakukan di kelas X. Wawancara, observasi, dan reflektif jurnal dilakukan pada setiap pelaksanaan pembelajaran. Analisis data oleh Miles et al (2013) melalui reduksi data, penyajian data serta verifikasi dan penarikan kesimpulan. Fokus pertanyaan wawancara dan observasi dilakukan pada aspek-aspek pembelajaran, seperti interaksi guru dan siswa, tanggapan siswa terhadap model pembelajaran yang diterapkan, serta 
aspek-aspek soft skills dan hard skills yang muncul selama proses pembelajaran

Model pembelajaran CRTT ini dikembangkan berdasarkan prinsip CRT oleh Hernandez et al (2013), yaitu content integration, facilitating knowledge construction, prejudice reduction, social justice, and academic development. Enam prinsip tersebut selanjutnya diintegrasikan dalam model pembelajaran CRTT yang dikembangkan dengan terdiri dari 5 tahap, yaitu self identification (identitas diri), cultural understanding (pemahaman budaya), collaboration (kolaborasi), critical reflections (berpikir refleksi kritis), transformative construction (konstruksi transformatif). Lima tahapan model dijelaskan sebagai berikut:

1. Self identification (identitas diri)

Tahapan ini merupakan tahap awal pemahaman identitas dan karakteristik siswa sebagai prinsip awal facilitating knowledge construction, prejudice reduction, dan social justice. Guru mencari informasi latar belakang siswa, karakteristik gaya belajar dan memberikan kesempatan kepada siswa untuk memahami karakteristik dirinya sendiri melalui reflektif jurnal.

2. Cultural understanding (pemahaman budaya)

Tahapan ini menerapkan prinsip content integration, prejudice reduction, dan social justice. Siswa difasilitasi untuk memahami budayanya, dengan mencari tahu berbagai sumber, termasuk melalui penugasan berdiskusi dengan keluarga terkait latar belakang budaya keluarga. Guru mengintegrasikan kimia dengan budaya, hal ini dapat dilakukan melalui artikel etnokimia, budaya, dan lain-lain.

3. Collaboration (kolaborasi)

Tahapan ini menerapkan prinsip facilitating knowledge dan academic development. Guru dapat menerapkan berbagai pendekatan student-centred seperti Jigsaw, STAD, dan lain-lain untuk diskusi terkait pemahaman konsep kimia. Guru memberikan tugas diskusi, debat, atau proyek berdasarkan artikel etnokimia. Siswa melakukan kolaborasi berdasarkan jenis penugasan yang diberikan.

4. Critical reflections (berpikir refleksi kritis)

Tahapan ini menerapkan prinsip facilitating knowledge dan academic development. Pada tahapan ini guru memfasilitasi setiap siswa dengan karakteristiknya untuk mengembangkan keterampilan berpikir, sehingga prinsip prejudice reduction, dan social justice telah diterapkan guru. Pada tahapan ini, siswa melakukan proses refleksi dan berpikir kritis terhadap masalah atau isu yang diberikan melalui diskusi atau debat.

\section{Transformative construction \\ (konstruksi} transformatif)

Tahapan ini menerapkan prinsip facilitating knowledge dan academic development. Siswa melakukan konstruksi pemahaman dan nilai berdasarkan pengalaman yang diberikan dan dapat mempresentasikan hasil proyek etnokimia di depan kelas berlandaskan latar budaya kelompoknya masing-masing. Siswa menuliskan reflektif jurnal mengenai proses transformasi/perubahan yang dialami baik dalam pemahaman konsep kimia atau identitas budayanya. Siswa diberikan tes pemahaman konsep kimia terfokus pada kemampuan berpikir tingkat tinggi.

Lima tahap pada model pembelajaran ini dideskripsikan pada gambar 1. Pada tahapan pembelajaran ini, integrasi etnokimia yang diterapkan menggunakan isu-isu terkait budaya dan konsep kimia dengan menggunakan artikel etnokimia yang terdapat pada tabel 1. Alur pembelajaran yang diterapkan sebagai berikut:

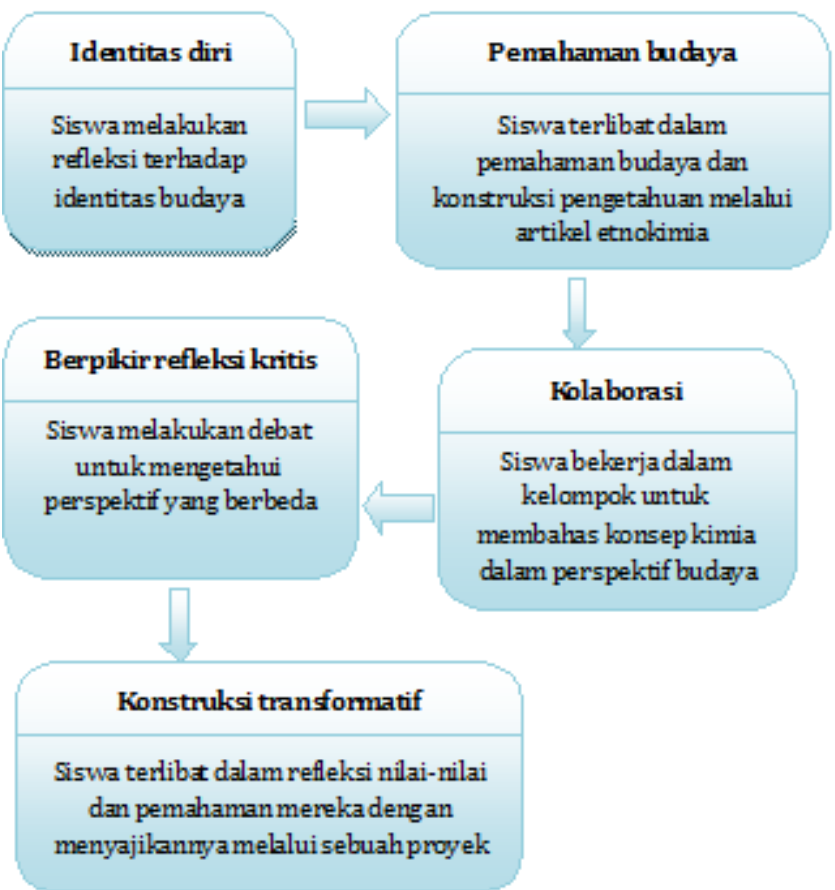

Gambar 1. Model pembelajaran CRTT (Rahmawati \& Ridwan, 2017; Rahmawati, et.al, 2019)

Beberapa artikel yang digunakan pada penelitian ini dan dikaitkan dengan konsep asam basa dan elektrolit yang diterapkan pada tahapan pemahaman budaya, antara lain:

Tabel 1. Artikel etnokimia

\begin{tabular}{lll}
\hline No. & Judul Artikel & Materi Kimia \\
\hline 1. & Cuka Bali Alami & Asam Basa \\
2. & $\begin{array}{l}\text { Ngeyeuh Seuruh Tradisi Sakral } \\
\text { Suku Sunda }\end{array}$ & Asam Basa \\
3. & $\begin{array}{l}\text { Jamasan, Solusi Keris anti } \\
\text { Korosi }\end{array}$ & Asam Basa \\
4. & $\begin{array}{l}\text { Nginang Warisan Ampuh Gigi } \\
\text { Kuat dan Sehat }\end{array}$ & Asam Basa \\
\hline
\end{tabular}




\begin{tabular}{lll}
\hline No. & Judul Artikel & Materi Kimia \\
\hline 5. & Moci Ala Japan van Java & Asam Basa \\
6. & $\begin{array}{l}\text { Pemanfaatan Air Kelapa Hijau } \\
\text { dalam Budaya Jawa }\end{array}$ & $\begin{array}{l}\text { Larutan elektrolit } \\
\text { dan non elektrolit }\end{array}$ \\
7. & $\begin{array}{l}\text { Jeruk Nipis si "Asam" } \\
\text { Larutan elektrolit } \\
\text { dan non elektrolit }\end{array}$ \\
8. & $\begin{array}{l}\text { Permanfaat } \\
\text { Peuyeum Cemilan Si Jawa }\end{array}$ & $\begin{array}{l}\text { Larutan elektrolit } \\
\text { dan non elektrolit }\end{array}$ \\
9. & Karat Peuyeum & $\begin{array}{l}\text { Larutan elektrolit } \\
\text { dan non elektrolit }\end{array}$ \\
\hline
\end{tabular}

Pada penelitian ini dilakukan analisa terhadap proses pembelajaran dan dampaknya terhadap perkembangan identitas budaya dan karakter siswa.

\section{Hasil dan Pembahasan}

\section{Pembelajaran CRTT terintegrasi etnokimia}

Penerapan CRTT terintegrasi etnokimia dilaksanakan dengan mengaitkan karakteristik siswa dan kebudayaan pembelajaran kimia dijabarkan pada prinsip-prinsip yang dikembangkan dalam model pembelajaran yang digunakan.

Content integration, salah satu aspek content integration adalah penyatuan konten materi dari berbagai budaya yang dilakukan melalui integrasi etnokimia yang diterapkan pada tahapan kedua pembelajaran yaitu pemahaman budaya. Aspek ini bertujuan menerapkan pendekatan yang sesuai dengan latar belakang siswa dan kehidupan sehari-hari. Integrasi etnokimia dilakukan menggunakan artikel kimia yang dikaitkan dengan tradisi atau kehidupan sehari-hari siswa. Artikel disusun oleh tim peneliti dan digunakan guru dalam pembelajaran. Artikel yang disusun divalidasi oleh ahli setiap konsep keilmuan dan budaya. Salah satu artikel yang berjudul "Air Kelapa Hijau sebagai Obat Tradisional." Artikel ini membahas tentang tradisi meminum air kelapa hijau pada wanita hamil dimana air kelapa hijau tersebut memiliki manfaat yakni kandungan senyawa elektrolit. Tradisi mengonsumsi air kelapa hijau sebagai obat untuk menyembuhkan beberapa penyakit, misalnya keracunan, memperlancar air seni, demam berdarah dan disentri. Beberapa mineral yang terkandung dalam air kelapa juga merupakan zat elektrolit, seperti $\mathrm{Na}$ (Natrium), Ca (Kalsium), Kalium (K), dan Magnesium $(\mathrm{Mg})$. Kandungan elektrolit yang dimiliki air kelapa dapat menggantikan ion tubuh yang hilang. Pada artikel disampaikan mineral yang terkandung dalam air kelapa yang merupakan garam dapat mengion dalam larutan dan menghantarkan listrik. Pembelajaran kimia yang dikaitkan dengan kehidupan sehari-hari dapat membuat peserta didik lebih memahami materi. Siswa akan merasa terbantu jika ada hal yang berkisambungan dengan apa yang membuat mereka mengetahui dengan pengetahuan yang baru. Hal ini tergambar pada reflektif jurnal peserta didik :

"Saya menjadi paham Bu ketika belajar dikaitkan dengan kehidupan sehari-hari lebih mudah untuk dipahami. Contohnya air kelapa mengandung elektrolit, ternyata alkohol dalam peuyeum itu non elektrolit"(Reflektif Jurnal Siswa 24, 21 Februari 2018)

Siswa lebih mudah memahami dalam materi elektrolit dan non elektrolit saat dikaitkan dengan budaya dari daerahnya. Siswa mampu menggolongkan larutan air kelapa sebagai larutan elektrolit juga alkohol dalam peuyem sebagai larutan non elektrolit. Peuyeum merupakan makanan yang berasal dari provinsi Jawa Barat. Peuyeum adalah tapai yang dibuat dari singkong yang difermentasi oleh ragi Saccharomyces cerevisiae. Alkohol diperoleh melalui fermentasi karbohidrat oleh ragi. Alkohol juga merupakan larutan yang tidak terionisasi sehingga tidak mempunyai daya hantar listrik.

Salah satu contoh artikel yang erat dengan konsep asam basa adalah penggunaan jeruk nipis dalam pencucian keris. Ritual jamasan pusaka pada keris terdiri dari beberapa langkah. Awalnya, keris direndam dalam air kelapa selama beberapa jam, kemudian digosok dengan jeruk nipis, dibilas dengan air bunga (terdapat 5 jenis bunga), diolesi minyak wangi (minyak non alkohol) dan terakhir di bakar diatas dupa atau kemenyan dengan cara mengasapnya (Jiwa, 2017)

Fungsi dari bahan-bahan yang terdapat dalam ritual tersebut ternyata dapat dijelaskan secara ilmu pengetahuan. Salah satunya adalah jeruk nipis yang efektif melapisi logam untuk mengurangi laju korosi pada logam. Jeruk nipis mengandung asam sitrat $\left(\mathrm{CH}_{2}(\mathrm{COOH})-\mathrm{COH}(\mathrm{COOH})-\mathrm{CH}_{2}(\mathrm{COOH})\right.$ yang dapat terionisasi dalam larutan. Keasaman asam sitrat dihasilkan dari tiga gugus karboksil (-COOH) yang dapat melepaskan proton $\left(\mathrm{H}^{+}\right)$dalam larutan. Pada saat keris digosok dengan jeruk nipis, ion sitrat akan menempel pada permukaan logam dan membentuk lapisan tipis yang menutupi permukaan logam. Lapisan ini memisahkan logam dari lingkungannya sehingga keris akan sukar terkorosi (Maryati, 2006).

Penggunaan artikel ini berdampak pada keingintahuan dan motivasi siswa. Selain itu, pada topik ini juga dapat dilakukan praktikum menggunakan bahan yang ada pada kehidupan sehari-hari sehingga siswa dapat menghubungkan langsung materi yang dipelajari dengan kebiasaan atau kebudayaan mereka Sebagaimana, reflektif jurnal yang ditulis oleh siswa:

"Saya membaca artikelnya dengan sungguhsungguh dan mengerjakan soal, tidak hanya soal yang 
kimianya saja, tapi juga tentang budayanya. Jadi saya lebih mengerti etnokimianya dan juga budayanya"(Wawancara Siswa 15, 8 Februari 2018)

" Praktikum dengan menggunakan bahan pada kehidupan sehari-hari, menarik, karena kita jadi mengetahui bahan-bahan yang ada di sekitar kita juga ada ilmu kimianya, serta bahan yang digunakan juga mudah ditemukan" (Reflektif jurnal Siswa 11, 1 Februari 2018).

Ketertarikan siswa pada pembelajaran, dapat menjadi motivasi siswa. Motivasi dan tujuan menjadi faktor utama keberhasilan siswa dalam kemampuan akademiknya.

Facilitating knowledge construction, aspek ini bertujuan untuk mengkonstruksi pengetahuan baru agar siswa mudah menerima konsep pembelajaran kimia dan untuk menjembatani pengalaman belajar sebelumnya dengan ilmu baru. Pengetahuan guru yang relevan dengan budaya memposisikan pengetahuan sebagai hal yang diciptakan terus menerus dan siswa sebagai konstruktor pengetahuan (Kelly-Jackson, 2011). Aspek ini mengharuskan siswa untuk memahami suatu artikel yang disesuaikan dengan pengetahuan siswa akan kebudayaan asalnya secara umum. Artikel dibuat sebagai wadah siswa dalam mengembangkan pengetahuannya. Guru melakukan tahapan ini dengan pertanyaan pengarah dan apersepsi. Beberapa siswa menanggapi pertanyaan guru dengan antusias. Tanggapan siswa cukup beragam, seperti mengaitkan tradisi tersebut dengan daerah asal orang tuanya sebagai berikut:

".... orang tua saya dari Jawa, di Jawa ada juga budaya minum air kelapa untuk obat”. Siswa lain juga mengatakan bahwa sampai saat sekarang, tradisi minum air kelapa sebagai obat masih dilakukan oleh keluarganya. Siswa secara umum antusias terhadap materi kimia yang dikaitkan dengan kebiasaan atau kehidupan sehari-harinya" (Catatan Guru 1, 25 Januari 2018)

"Kami banyak mendapatkan informasi, karena pembelajaran ini dikaitkan dengan keseharian kami, karena sangat jarang pembelajran terutama di kimia kita kaitkan dengan kehidupan sehari-hari, biasanya kalo pembelajaran kimia terutama fokus dengan kimia membahas tentang ini, tentang itu, jadi seakan -akan kami males untuk mengikutinya apalagi dengan rumus-rumusnya yang rumit, karena ini dikaitkan dengan kehidupan sehari-hari jadi kita mulai tergugah untuk mengikuti pembelajaran" (Wawancara Siswa 20, 10 Januari 2018)
Pembelajaran yang kontekstual ini diharapkan dapat mengembangkan soft skills siswa sesuai dengan pernyataan Syahbana (2012) bahwa pembelajaran kontekstual memberikan dampak yang signifikan terhadap kemampuan berpikir kritis siswa.

Prejudice reduction, aspek ini bertujuan untuk membangun suasana pembelajaran yang positif dan nyaman bagi seluruh siswa dengan mengurangi prasangka oleh guru (Hernandez, Morales, \& Shroyer, 2013). Pembelajaran yang relevan dengan budaya diciptakan oleh guru untuk meningkatkan hubungan sosial dengan siswa, di antara siswa yang mendukung pembelajaran masyarakat secara kolaboratif (KellyJackson, 2011). Proses pembelajaran menggunakan artikel etnokimia mengajak siswa untuk bercerita tentang asal dan kebudayan daerah mereka masingmasing. Dengan demikian, siswa merasa nyaman untuk berbagi cerita dengan guru. Sebagaimana hasil wawancara dan reflektif jurnal siswa berikut:

"Saya mencari ke Google dan mencari tahu mengenai penggunaan jeruk nipis pada pencucian keris"(Wawancara siswa 8, 1 Februari 2018)

"Bapak Saya Aceh, Ibu Saya Solo. Kalau makanan khas ada dari Aceh, namanya gulai ikan padeh, menggunakan kunyit dan bumbu asam

(Reflektif Jurnal Siswa 7, 31 Januari 2018)

Hasil di atas menunjukkan bahwa pembelajaran berbasis budaya mempengaruhi antusiasme siswa dalam menceritakan kebudayaannya. Siswa merasa bangga dengan latar belakang budaya yang mereka miliki.

Social Justice, aspek ini merupakan kemampuan siswa agar berani menunjukkan status dirinya, mendorong siswa untuk menjadi warga negara yang baik, dan menjadi bagian dari agen perubah (Hernandez, Morales, \& Shroyer, 2013). Pembelajaran pada aspek ini dilakukan dengan melakukan kegiatan debat role playing, diskusi artikel, dan praktikum. Guru juga harus membantu siswa agar mengenali siapa dirinya yang dilakukan sejak awal pembelajaran melalui tahapan self identification. Berikut adalah contoh reflektif jurnal siswa yang mampu mengidentifikasi dirinya sendiri.

"Saya ini orangnya pemalu, padahal paham tetapi sulit untuk mengungkapnya terutama pada saat ditunjuk oleh guru, saya langsung deg-degan, panas dingin"'(Reflektif jurnal peserta didik 21, 8 Januari 2018)

Siswa di atas mampu mengidentifikasi dirinya sebagai seseorang yang pemalu dalam mengungkapkan 
pemahamannya terlebih lagi saat guru menunjuk siswa tersebut untuk menjawab soal.

Model pembelajaran ini diharapkan dalam membantu siswa mengenal latar belakang budaya, karakteristik, dan cara belajarnya, sehingga, siswa dapat mengatasi permasalahan dalam minat belajar dirinya. Hal ini tergambar pada catatan guru bahwa siswa melakukan refleksi terhadap kemampuannya dalam mengerjakan soal ataupun problem yang diberikan guru. Pada tahapan ini, siswa diarahkan untuk memiliki kesadaran terhadap kemampuan dirinya. Siswa memiliki kesadaran diri (self awareness), yang memungkinkan orang lain untuk mengamati dirinya atau membedakan dirinya dengan orang lain dimana seseorang menempatkan diri pada suatu keadaan (Maharani, 2016). Status atau peran siswa diartikan sebagai sebuah latar belakang siswa yang dimiliki, sehingga menjadikannya khas dan berbeda dengan yang lain (Hernandez, 2013).

Pembelajaran ini juga mengaitkan tradisi suatu daerah ataupun kehidupan siswa sehari-hari. Artikel dijadikan sebagai bahan untuk debat role playing. Debat yang dilaksanakan saat pembelajaran memunculkan soft skills siswa diantaranya menghargai pendapat orang lain, cinta tanah air, peduli lingkungan, empati komunikasi dan rasa ingin tahu. Hal ini sesuai dengan penelitian Ridwan, Rahmawati, Hadinugrahaningsih, dan Nurbaity (2016) yang menyatakan bahwa pembelajaran kimia dengan menggunakan debat artikel dapat mengembangkan karakter siswa, terutama dalam berargumentasi, empati komunikasi dan percaya diri.

Academic Development, aspek ini dapat membantu guru untuk menciptakan peluang dalam mengembangkan akademik siswa untuk mencapai kesuksesan akademik (Edward \& Edick, 2013; Hernandez, 2013). Pembelajaran kimia dengan model pembelajaran CRTT dilakukan dengan metode Think Pair Share, diskusi, praktikum, ceramah, dan debat. Metode yang digunakan merupakan metode kooperatif. Hal ini bertujuan untuk membangun interaksi positif antar siswa tanpa memperhatikan latar belakang budaya mereka. Salah satu cara guru untuk memotivasi siswa yaitu dengan menggunakan metode yang bervariasi. Pembelajaran ini dapat membangkitkan kreativitas, mengembangkan informasi, dan menjalin kerja sama kelompok. Guru berperan sebagai fasilitator selama proses pembelajaran, sebagaimana pernyataan siswa berikut:

"Guru berperan baik, mampu memberi informasi dan menjelaskan disaat murid bertanya apa yang tidak di ketahui" (Reflektif jurnal siswa 2, 25 Januari 2018)
"Kami berusaha mencari solusi dari beberapa masalah yang diberikan selama debat dan diskusi" (Wawancara siswa 23, February 20, 2018)

Pernyataan siswa menunjukkan bahwa guru telah membantu siswa untuk memahami materi. Peran guru sangat penting dalam pembelajaran karena tidak hanya memfasilitasi siswa, namun juga sebagai konsultan dan mediator dalam pembelajaran (Ladson-Billings, 1995). Selain itu, beberapa siswa juga mengungkapkan bahwa guru telah membantu siswa dalam memahami konsep.

\section{Pengembangan Soft Skills Siswa}

Penerapan pendekatan pembelajaran ini, berdampak terhadap perkembangan soft skills siswa antaranya bekerjasama, berpikir kritis, peduli lingkungan, kesadaran sosial dan budaya, cinta tanah air, dan rasa ingin tahu.

\section{Bekerja sama}

Bekerja sama memungkinkan siswa brinteraksi dengan orang lain dan bertanggung jawab atas tindakan mereka, termasuk belajar dan menghargai kemampuan serta kontribusi teman sebayanya. Pada proses kerja kelompok, terdapat pembagian tugas dan penerimaan tanggung jawab di antara anggota kelompok terhadap hasil kerja kelompok tersebut (Laal \& Sayed, 2011)

Model pembelajaran ini mendorong siswa untuk bekerja secara berkelompok yang berdampak terhadap kemampuan kerja sama siswa. Berdasarkan analisis data dilakukan siswa menyatakan bahwa kerja sama merupakan salah satu perkembangan soft skills yang dialami oleh siswa, seperti pernyataan siswa berikut.

"Nilai bekerja sama dapat dilihat saat seluruh anggota bekerja sama dalam menyelesaikan tugastugas, seperti untuk menjawab pertanyaan dan mengerjakan tugas projek. Karena tanpa adanya kerja sama maka tugas tidak akan cepat selesai sehingga dalam mengerjakan tugas-tugas yang diberikan harus saling bekerja sama dan saling membantu satu sama lain" (Reflektif jurnal siswa 11, 24 Februari 2018)

"Saya senang belajar berkelompok, Bu. Karena saat saya tidak paham terhadap suatu materi, teman saya yang lain dapat menjelaskannya pada saya sehingga saya jadi paham" (Reflektif jurnal siswa 17, 25 Januari 2018)

Pada tahap kolaborasi ini, siswa cenderung tidak takut untuk bertanya, karena siswa akan berdiskusi dengan teman sebayanya.

\section{Berpikir Kritis}


Berpikir kritis mencakup keterampilan komponen dalam menganalisis argumen, membuat kesimpulan dengan penalaran induktif atau deduktif, menilai atau mengevaluasi, dan membuat keputusan atau memecahkan masalah. Berpikir kritis melibatkan keterampilan dan disposisi kognitif. Sifat-sifat ini, yang dapat dilihat sebagai sikap atau kebiasaan pikiran yang mencakup keterbukaan pikiran, rasa ingin tahu, fleksibilitas, kecenderungan untuk mencari alasan, keinginan untuk mendapatkan informasi yang baik, rasa hormat, dan kemauan untuk melihat sesuatu dari berbagai sudut pandang. Hal ini tertuang dalam catatan observasi berikut:

"Kegiatan pembelajaran mampu membangkitkan rasa penasaran para peserta didik dikarenakan seringnya membahas isu budaya yang berkaitan dengan materi yang sedang dipelajari. Selain itu, hal ini terlihat dari semakin banyaknya peserta didik yang berani bertanya dan sudah tidak malu-malu lagi selama proses pembelajaran. Peneliti berperan aktif dalam memotivasi dan membimbing peserta didik dalam meluruskan jawaban yang diberikan."(Catatan observer 1, 24 Januari 2018)

Berdasarkan catatan observer di atas, siswa menjadi lebih aktif bertanya selama proses pembelajaran. Guru juga memfasilitasi proses belajar siswa melalui pertanyaan yang selanjutnya didiskusikan oleh siswa. Hal ini bertujuan untuk mengasah kemampuan berpikir kritis siswa. Berdasarkan hasil observasi, pembelajaran yang dilaksanakan cukup aktif, dimana siswa sering bertanya mengenai materi yang disampaikan dan menganalisisnya melalui aplikasi dalam kehidupan sehari-hari. Kemampuan siswa dalam memecahkan masalah berkaitan dengan salah satu keterampilan berpikir kritis yaitu inferensi, yang mana siswa dapat mempertanyakan pernyataan, mengemukakan suatu alternatif, menarik kesimpulan, memecahkan masalah dan dapat mengambil keputusan. Pembelajaran ini dapat memotivasi siswa pada peranannya sebagai siswa yang berprestasi, dengan memupuk rasa ingin tahu dan berpikir kritis serta mencintai kebudayaannya.

\section{Peduli Lingkungan}

Kepedulian terhadap lingkungan oleh siswa dapat dibangun dengan pengintegrasian konsep kimia dalam kehidupan sehari-hari dengan kebudayaan di sekitar siswa melalui berbagai artikel yang disajikan. Hal ini sesuai dengan peneliti Villegas dan Lucas (2002) mengemukakan bahwa ketika memilih artikel dalam pembelajaran di dalamnya harus melibatkan unsur yang mencerminkan pengalaman pribadi, perasaan, dan pikiran siswa mereka. Artikel yang diberikan pada siswa merupakan salah satu usaha untuk menyadarkan siswa agar menjaga lingkungan. Salah satu contoh adalah saat siswa melaksanakan debat tentang baterai primer dan baterai sekunder. Debat dilaksanakan dengan cara role playing (bermain peran) dimana kelas dibagi menjadi 3 kelompok besar. Saat debat berlangsung, muncul sebuah pendapat yang menarik perhatian guru, dimana siswa berpendapat mengenai pemakaian baterai primer dapat mencemari lingkungan. Menurut pendapatnya, baterai primer yang hanya bisa sekali pakai akan terus menerus dibuang oleh penggunanya, sehingga lama kelamaan akan menumpuk dan berujung pada pencemaran lingkungan (Catatan guru, 27 Februari 2017). Hal ini sesuai dengan penelitian Bernd (2008) yang menyatakan bahwa pembelajaran dengan cara yang menarik dapat dilakukan untuk memasukkan komponen soft skills ke dalam pembelajaran hard skills, yang mana tanpa disadari soft skills akan berkembang dengan sendirinya.

\section{Kesadaran Budaya dan Sosial (Social and Cultural Awareness)}

Model pembelajaran CRTT terintegrasi etnokimia memfasilitasi kesadaran budaya dan sosial siswa. Menurut Semali (2013), kelas menerapkan CRTT, pengajaran dan pembelajaran yang efektif terjadi dalam konteks yang berpusat pada budaya yang menjadi potensi keberhasilan belajar siswa. Hampir setiap aspek pada model pembelajaran CRTT dapat mendukung terbentuknya kesadaran sosial budaya yang mencakup empati komunikasi, bertanggung jawab, disiplin, dan kepedulian sosial. Salah satu ciri pendekatan $C R T$ yaitu memperhatikan latar belakang budaya dan karakter siswa yang dapat menstimulasi munculnya kesadaran sosial.

Penerapan kolaborasi telah mampu mengembangkan sikap kesadaran sosial siswa dalam bekerja sama dan menghargai perbedaan dengan teman lain. Artikel etnokimia yang diberikan telah membantu siswa pada kesadarannya mempelajari kebudayaan dan sosial kemasyarakatan. Hal ini tertuang dalam catatan observasi sebagai berikut:

"Metode pembelajaran yang diterapkan membuat siswa mampu membangun interaksi dalam perbedaan dengan orang lain ..."(Catatan Obsever 2, 30 Januari 2018)

Hal ini juga merupakan dampak praktikum yang dilaksanakan dengan menggunakan bahan yang ada dalam kehidupan siswa sehari-hari, seperti beberapa minuman isotonik berbagai merek dan air kelapa muda. Pada pembelajaran praktikum, siswa dapat mengetahui minuman yang mereka uji termasuk larutan elektrolit atau non elektrolit, sehingga siswa 
mampu mengetahui konsep dari larutan elektrolit tersebut yang dikaitkan dengan aplikasinya dalam budaya di lingkungannya. Hal ini terdapat pada pernyataan siswa di bawah ini.

"Saya menyadari perbedaan budaya dengan teman-teman dan mempelajari budaya saya sendiri" (Wawancara Siswa 10, 31 Januari 2018)

Siswa belajar untuk mengenal budayanya dan berinteraksi dengan orang lain, tanpa mengabaikan pemahaman konsep kimia yang disampaikan.

\section{Cinta Tanah Air}

Pembelajaran ini menumbuhkan soft skills cinta tanah air, siswa akan memahami keberagaman yang dimiliki oleh budayanya, peka terhadap kekayaan budaya, dan berusaha untuk melestarikan budayanya. Sebagaimana reflektif jurnal berikut:

"Tradisi ini merupakan tradisi yang positif karena banyak manfaatnya, seperti untuk menyembuhkan penyakit dan mencegah timbulnya penyakit. Tradisi ini harus tetap dijalani dan dikembangkan" (Reflektif jurnal siswa 15, 30 Januari 2018)

Berdasarkan reflektif jurnal tersebut terlihat bahwa siswa memberikan respon positif terhadap tradisi yang terdapat pada artikel. Air kelapa hijau sebagai obat tradisional menurut siswa baik untuk dilestarikan agar tidak hilang, penggunaan air kelapa hijau pada tradisi tujuh bulanan di jawa juga harus dilestarikan. Sikap siswa tersebut menyatakan bahwa siswa telah menghormati tradisi yang dilakukan oleh nenek moyang dan ingin menjaganya agar tradisi tersebut tetap terjaga eksistensinya. Siswa merasa kekayaan yang dimiliki begitu banyak, seperti kegunaan sirih untuk kesehatan gigi dengan tradisi ngenyeuh sereuh pada tradisi suku sunda, penggunaan air jeruk nipis untuk membersihkan keris pada acara jamasan, dan sebagaikan.

\section{Rasa Ingin Tahu}

Pembelajaran kimia dengan pendekatan $C R T$ merupakan pembelajaran yang baru bagi siswa, sehingga mendorong keingintahuan siswa. Rasa ingin tahu merupakan keinginan untuk menyelidiki dan memahami suatu fenomena atau pernyataan (Samani \& Hariyanto, 2012). Berikut merupakan contoh sikap siswa yang ingin tahu dalam pembelajaran hari itu.

"Menurut saya pembelajaran hari ini sangat berbeda dari sebelumnya, karena menggunakan metode yang baru sehingga semua peserta didik mencari tahu tentang apa yang sedang dibahas melalui internet, buku, dll."(Reflektif jurnal siswa 04, 21 Februari 2018)

Berdasarkan pernyataan siswa di atas, menandakan bahwa pembelajaran yang dilaksanakan membuat siswa antusias dengan pembelajaran kimia karena variasi penggunaan metode yang disesuaikan dengan karakteristik siswa, serta kaitannya dengan budaya siswa. Rasa ingin tahu siswa terlihat dari antusias siswa mencari tahu dari berbagai sumber mengenai materi yang akan dibahas juga saat siswa memberikan pertanyaan. Artikel etnokimia yang diberikan membuat siswa ingin mengetahui tentang berbagai informasi mengenai artikel tersebut, misalnya, saat pembahasan artikel air kelapa hijau, banyak siswa yang menanyakan terkait manfaat dari air kelapa hijau tersebut dan menghubungkannya dengan kehidupan sekitar atau dengan pemahaman pengetahuan mereka. Hal ini menunjukkan bahwa artikel kimia yang diberikan mendapat respon positif dari siswa. Rasa ingin tahu dapat meningkatkan intensitas belajar dan memori, dengan adanya rasa ingin tahu siswa akan mengkonseptualisasikan keingintahuan dan motivasi, mempelajari hal baru, kompleksitas, dan informasi lainnya (Ondeyer, 2016).

Model pembelajaran CRTT dapat menunjang terbentuknya soft skills siswa dan sesuai dengan pengembangan karakter pada kurikulum 2013. Pembelajaran dengan pendekatan budaya dapat membantu siswa dalam memahami budayanya serta budaya orang lain yang berdampak pada ketertarikan siswa terhadap pembelajaran kimia dalam sudut pandang yang berbeda. Berdasarkan hasil analisis data secara keseluruhan, terutama pada refleksi guru, pembelajaran ini memiliki tantangan dalam penerapannya meliputi integrasi budaya dalam konsep kimia, perubahan paradigm siswa dan guru, serta keterbatasan waktu. Namun pendekatan ini dapat dikembangkan dalam berbagai topik dalam pembelajaran kimia.

\section{Kesimpulan}

Pembelajaran kimia melalui model pembelajaran CRTT pada materi asam basa, serta elektrolit dan non elektrolit telah memfasilitasi siswa dalam pengembangan soft skills, pengetahuan kimia, identitas budaya, dan karakternya. Model pembelajaran CRTT mampu mengembangkan soft skills siswa yakni bekerja sama, berpikir kritis, kepemimpinan, peduli lingkungan, cinta tanah air, kesadaran sosial dan budaya, dan rasa ingin tahu. Hasil penelitian selama dua tahun menunjukkan bahwa model pembelajaran ini membutuhkan kreativitas guru dalam mengintegrasikan budaya dengan konsep kimia, 
keterbatasan waktu, serta perubahan paradigma siswa dan guru. Model pembelajaran CRTT selanjutnya dapat dikembangkan dalam beberapa konsep kimia lainnya ataupun mata pelajaran lain dengan mengkaji lebih dalam dampaknya terhadap proses dan hasil belajar siswa, serta kompetensi guru.

\section{Daftar Pustaka}

Aikenhead, G. S. I. (2000). Renegotiating the culture of school science. In J. L. R. Millar, \& J. Osborne (Ed.), Improving Science Education: The Contribution of Research (pp. 245-264). Birmingham, UK: Open University Press.

Arifah. (2014). Kurikulum 2013 implementasikan grand design kebudayaan. [Online]. http://kebudayaan.kemdikbud.go.id/ditkt/2014/07/0 7/kurikulum-2013-implementasikan-grand-designbidang-kebudayaan/, diakses pada 20 Mei 2017

Arthur, J. \& Wilson, K. (2010). In new research directions in character and values education in the UK. T. Lovat et al. (eds.), International Research Handbook on Values Education and Student Wellbeing. Springer.

Atran, S. (1991). Social science information. Ethnoscience Today, 30, 595 - 662.

Badan Pusat Statistik. (2010). Hasil sensus penduduk 2010. [Online]. https://sp2010.bps.go.id, diakses pada 12 Juli 2010.

Bernd, S. (2008). The importance of soft skills: Education beyond academic knowledge. NAWA Journal of Language and Communication. 2(1): 146-154.

Cartledge, G. \& Kourea, L. (2008). Culturally responsive classrooms for culturally diverse students with and at risk for disabilities. Exceptional Children, 74, 351-371.

Chang, R. 2003. Kimia dasar konsep-konsep inti, edisi 3. Jakarta: Erlangga.

Deepa, Seth, and Manisha Seth. (2013). Do soft skills matter? Implications for educators based on recruiters' perspective. IUP Journal of Soft Skills, 7(1), 7-20.

Gabel, D. (1999). Improving teaching and learning through chemistry education research: a look to the future. Journal of Chemical Education, 76 (4), 548553.

Gay, G. (2000). Culturally responsive teaching: Theory, practice, and research. New York: Teachers College Press.

Gay, G. (2010). Culturally responsive teaching: Theory, research, and practice (2nd ed.), New York, NY: Teachers College.

Gollnick, D. M., \& Chinn, P. C. (2017). Multicultural education in a pluralistic society. Boston: Pearson.

Hernandez, C.M., Morales, A.R. \& Shroyer, M.G. (2013). The development of model culturally responsive science and mathematics teaching. Manhattan: Springer.

Hutcheon, P.D. (1999). Building character and culture. Wesport, Connecticut: Praeger.

Jiwa, K.J.B. (2017). Makna jamasan pusaka. http://www.kerispusakajawa.com/2017/07/maknajamasan-pusaka.html, diakses 30 Juli 2017

Kelly-Jackson. (2011). Meeting their fullest potential: the beliefs and teaching of a culturally relevant science teacher. Scientific Reasearch Creative Education, 2(4), 408-413.

Kemdikbud (2016). Permendikbud No.21 Tahun 2016, Standar Isi. Jakarta: Kemdikbud.

Kemdikbud. (2016). Analisis kearifan lokal ditinjau dari keberagaman budaya. Jakarta: Pusat Data dan Statistik Pendidikan dan Kebudayaan, Kemendikbud.

Koballa. (2010). Perspective gymnasium teachers conceptions of chemistry an teaching. International Journal of Science Education, 22(2), 215-217.

Laal, M., Seyed M. G. (2011). Benefits of collaborative learning. Procedia, social and behavioral sciences, 31, 486-490.

Ladson-Billings, G. (1995). Toward culturally relevant pedagogy. American Educational Research Journal, 32(3), 465-491.

Maharani, L, \& Mustika, M. (2016). Hubungan self awareness dengan kedisiplinan siswa kelas VIII di SMP Wiyatama Bandar Lampung. Lampung: IAIN Raden Intan Bandar Lampung 
Marcial, Dave E. (2012). Investigating soft skills among information technology managers in higher education institutions in the Philippines. Paper presented at the 5th International Conference of Education, Research and Innovation, Madrid, ES, November 19-21.

Maryati, E. (2006). Asam Sitrat sebagai lapisan pelindung untuk mengurangi. Laju korosi pada logam. Skripsi. Departemen Kimia FMIPA IPB. Bogor: IPB

Miles, M.B., \& Huberman, M., \& Saldana, J. (1992). Qualitative data analysis: A method sourcebook. New York: SAGE Publications.

Mubah. A.S. (2011). Strategi meningkatkan daya tahan budaya lokal dalam menghadapi arus globalisasi. Departemen Hubungan Internasional, FISIP, Universitas Airlangga, Surabaya, 24(4), 302308.

Nisa, A, Sudarmin, dan Samini. (2015). Efektivitas penggunaan modul terintegrasi etnosains dalam pembelajaran berbasis masalah untuk meningkatkan literasi sains siswa. Unnes Science Education Journal, 4(3): 1049-1056

Nursaadah, E. , Wijayanti, I.E., Zidny, R. , Solfarina, Aisyah, R.S.. (2017). Inventarisasi pengetahuan etnokimia masyarakat Baduy untuk pembelajaran kimia. Prosiding Seminar Nasional Pendidikan FKIP UNTIRTA.

Ondeyer, et all. (2016). Instrinsic motivation, curiosity, and learning: Theory and applications in educational technologies. Science Direct, 229, 257284.

Otasevic, K. (2013). Cultural diversity and cultural identity in globalization. http://www.wseas.us/elibrary/conferences/2013/Chania/AEBDb/AEBDb21.pdf, diakses pada 10 Juni 2017

Rahmawati, Y., Ridwan, A., Rahman, A., \& Kurniadewi, F. (2019). Chemistry students' identity empowerment through etnochemistry in culturally responsive transformative teaching (CRTT). J. Phys.: Conf. Ser., 1156 012032. doi:10.1088/1742$6596 / 1156 / 1 / 012032$

Rahmawati, Y. \& Taylor, P.C. (2015). Moments of critical realisation and appreciation: a transformative chemistry teacher reflects. Reflective Practice, 16, $31-42$.
Rahmawati, Y. \& Taylor, P.C. (2017). The fish becomes aware of the water in which it swims": revealing the power of culture in shaping teaching identity. Culture Studies Science Education, https://doi.org/10.1007/s11422-016-9801-1 (online first).

Rahmawati, Y., \& Ridwan, A. (2017). Empowering students' chemistry learning: The integration of ethnochemistry in culturally responsive teaching. Chemistry: Bulgarian Journal of Science Education, 6(6), 813-830.

Rahmawati, Y., Ridwan, A., Rahman, A., \& Kurniadewi, A. (2019). Chemistry students' identity empowerment through etnochemistry in culturally responsive transformative teaching (CRTT). International Conference of Chemistry (ICCHEM) 2018. IOP Conf. Series: Journal of Physics: Conf. Series 1156 (2019) 012032. IOP Publishing. doi:10.1088/1742-6596/1156/1/012032

Rahmawati, Y., Nurbaity, \& Marheni (2014). Pembelajaran dilemmas stories dalam upaya pengintegrasian nilai-nilai karakter dan budaya serta pengembangan soft skills dalam pembelajaran kimia. Laporan Penelitian. Jakarta: Universitas Negeri Jakarta

Ridwan, Rahmawati, Hadinugrahaningsih, \& Nurbaity. (2016). Integration of a socio-critical and problem oriented approach in chemistry learning for students soft skills development. MIER journal of educational studies trends and practices, 7(1), 3341.

Samani, M dan Hariyanto. (2012). Pendidikan karakter: Konsep dan model. Remaja Rosdakarya: Bandung

Sarwanto, \& Budiharti, R. (2013). Identifikasi sains asli (indigenous science) sistem pranata mangsa melalui kajian etnosains. Artikel Seminar Nasional Pendidikan Biologi, FKIP UNS. Solo: UNS.

Semali, L. (2013). The iSPACES Framework to restructure culturally responsive secondary science curriculum in Tanzania. Journals of University of Alberta libraries, 8(2), 32-46.

Shidiq, A.S. (2016). Pembelajaran sains kimia berbasis etnosains untuk meningkatkan minat dan hasil belajar siswa. Seminar Nasional Kimia dan Pendidikan Kimia, FKIP UNS, 14 Mei 2016.

Suastra, I.W. (2005). Merekonstruksi sains asli (indigenous science) dalam rangka 
mengembangkan pendidikan sains berbasis budaya lokal di sekolah: Studi etnosains pada masyarakat Penglipuran Bali. Disertasi. Bandung: Universitas Pendidikan Indonesia

Sudarmin , Febu, R., Nuswowati , M., \& Sumarni, W. Development of ethnoscience approach in the module theme substance additives to improve the cognitive learning outcome and student's entrepreneurship. The 3rd International Conference on Mathematics, Science and Education 2016 IOP Publishing IOP Conf. Series: Journal of Physics: Conf. Series 824 (2017) 012024.

Suryono, H. (2008). Konfigurasi identitas nasional, nasionalisme dalam era globalisasi suatu harapan dan tantangan. MIIPS, 7(2), 157-163.
Syahbana, A. (2012). Peningkatan kemampuan berpikir kritis matematis siswa SMP melalui pendekatan contekstual teaching and learning. Edumatika, 2(1): 45-57.

Taber, K. (2002). Alternative conceptions in chemistry: Prevention, diagnosis and cure. London: The Royal Society of Chemistry.

Villegas, A. M., \& Lucas, T. (2002). Preparing culturally responsive teachers. Journal of Teacher Education, 53(1), 20-32. doi:10.1177/002248710205300100 